\title{
Pressure loss and sound generated in a miniature pig airway tree model
}

\begin{abstract}
Background: Pulmonary auscultation is a common tool for diagnosing various respiratory diseases. Previous studies have documented many details of pulmonary sounds in humans. However, information on sound generation and pressure loss inside animal airways is scarce. Since the morphology of animal airways can be significantly different from human, the characteristics of pulmonary sounds and pressure loss inside animal airways can be different.
\end{abstract}

Objective: The objective of this study is to investigate the sound and static pressure loss measured at the trachea of a miniature pig airway tree model based on the geometric details extracted from physical measurements.

Methods: In the current study, static pressure loss and sound generation measured in the trachea was documented at different flow rates of a miniature pig airway tree.

Results: Results showed that the static pressure and the amplitude of the recorded sound at the trachea increased as the flow rate increased. The dominant frequency was found to be around $1840-1870 \mathrm{~Hz}$ for flow rates of $0.2-0.551 \mathrm{it} / \mathrm{s}$.

Conclusion: The results suggested that the dominant frequency of the measured sounds remained similar for flow rates from 0.20 to 0.551 it/s. Further investigation is needed to study sound generation under different inlet flow and pulsatile flow conditions.

Keywords: airway tree, static pressure, trachea, sound generation, pulsatile flow
Volume 3 Issue $6-2017$

\author{
Md Khurshidul Azad, Amirtaha Taebi, Joseph \\ H Mansy, Hansen A Mansy \\ University of Central Florida, USA
}

Correspondence: Md Khurshidul Azad, Biomedical Acoustics Research Laboratory, University of Central Florida, 4000 Central Florida Blvd., Orlando, FL 328I6, USA, Tel +I (407) 9141758, Email khurshid@knights.ucf.edu

Received: November 09, 2016 | Published: September 12, 2017

\section{Introduction}

Several computational and experimental studies of fluid dynamics and acoustic propagation in the pulmonary system were carried out to investigate sound and flow characteristics for various respiratory disease such as Asthma, COPD, and pneumothorax. Since certain pulmonary conditions affect airway diameter and resistance, information about pressure losses in airways may be useful for diagnosis of pulmonary conditions or for patient monitoring. Earlier studies of sound propagation in the airways and lungs demonstrated the utility of these sounds for detecting various pulmonary conditions. ${ }^{1-8}$ Sound propagation in the pulmonary system have been studied using animal ${ }^{3,9,10}$ and benchtop ${ }^{11,12}$ experiments. Numerical models ${ }^{13-18}$ were also developed and validated using animal experiments. ${ }^{19-21}$

Earlier studies ${ }^{22,23}$ measured pressure loss in model of human airways. Olson et al. ${ }^{24}$ suggested that the coefficient of resistance due to flow inside airways is dependent on branching angle of a bifurcation; increase in cross sectional area from parent branch to daughter branches, and lengths of each branch in a bifurcation. While pressure and sound inside the airways were widely studied for humans, less information are available for pressure changes and sound generation inside pig airways. It is important to establish information for the airways of certain animal as animal models are often used in medical research. The objective of this research is to study static pressure losses and sound generation of a miniature pig airway tree.

\section{Materials and methods}

The experimental setup (Figure 1) consists of two axial fans connected in series with a honeycomb between them. The honeycomb helped reduce the turbulence and create axial flow at the second fan inlet. A $100 \mathrm{~mm}$ diameter duct was connected to the fan setup outlet and carried the flow into the sound isolation chamber (Model: 4260S, WhisperRoom Inc., Knoxville, TN) where experiments were performed. The duct was then connected to a contraction with inlet and outlet diameter of $100 \mathrm{~mm}$ and $10 \mathrm{~mm}$, respectively. The contraction outlet supplied air to an airway model of miniature pig. The airway tree model was built in SolidWorks (2012, SolidWorks corporation, Concord, MA.) based on the geometric features reported in earlier studies of pig airways. ${ }^{7,25-28}$ The resulting CAD model was 3D printed using a Desktop 3D printer (MBot3D, El Paso, TX, model: MBot Grid 2 ) at a print resolution of $0.2 \mathrm{~mm}$. A pressure tap was drilled at the trachea $2 \mathrm{~cm}$ upstream of the carina to measure the pressure and sound (Figure 2).

A diaphragm pressure transducer (Model: DP 103, diaphragm: 8-06, Validyne Engineering, CA,) with full scale input of $0.35 \mathrm{~cm}$ of water, accuracy of $0.25 \%$ of full scale, and sensitivity of about $0.3 \mathrm{~V} /$ $\mathrm{Pa}$ was used to measure the static pressure at the trachea. The pressure transducer was calibrated using a hot wire anemometer (Model DT8880 , CEM, Shenzhen, China, range: $0.1 \sim 25 \mathrm{~m} / \mathrm{s}$, resolution: $0.01 \mathrm{~m} / \mathrm{s}$, accuracy: $\pm 5 \% \pm 0.1$ ) and a pitot tube (Model: PAA-6-KL, United Sensor Corporation, $\mathrm{NH}$ ) inside a wind tunnel that has uniform velocity distribution in the test section (except for a thin boundary layer). To calibrate the pressure transducer, the pitot tube was connected to the pressure transducer and placed inside a wind tunnel while the hot wire was placed at the same streamwise location (outside the boundary layer). The measured hot wire velocities at different flow rates were used to calibrate the pressure transducer. Sound was recorded using a probe mic (Model: ER-7C Probe Microphone Series B, Etymotic 
Research Inc., IL) with a sensitivity: $50 \mathrm{mV} /$ Pascal. The static pressure and sound at the trachea were acquired using LabVIEW (Ver 2015, National Instruments, Austin, TX) with a data acquisition card (Model: NI 9215, National Instruments, Austin, TX, resolution: $0.305 \mathrm{mV}$ ). The flow rate was measured by placing the airway model inside a thin airbag of maximum volume of 6liters. The time needed to fill the maximum bag volume was recorded using a stopwatch (resolution: 0.01 second). Flow rate was then calculated using the recorded time and airbag volume.

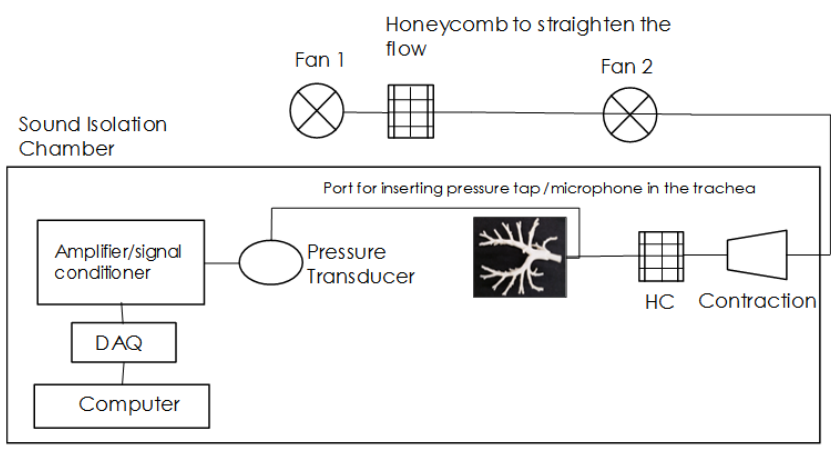

Figure I Experimental setup.

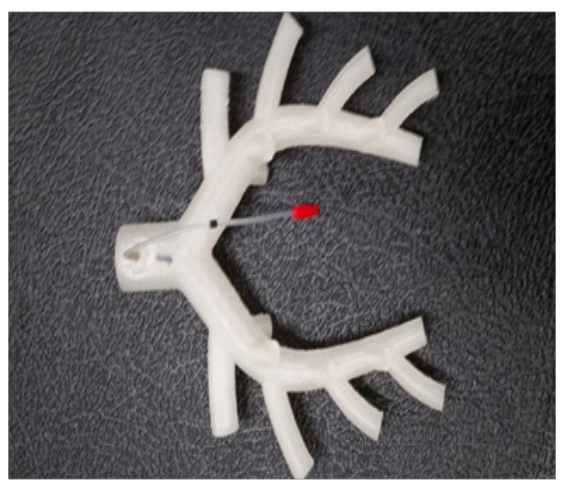

Figure 2 Miniature pig airway tree model with small pressure tap at the trachea to measure pressure and sound.

\section{Results}

Hot wire velocities were plotted against the pressure transducer voltages at different flow rates inside the wind tunnel (Figure 3 ). The velocities were found to be proportional to the transducer output raised to the power of $\sim 0.6$, which is close to the theoretical value of 0.5 . The velocity values were converted to dynamic pressure using the equation:

$$
q=\frac{1}{2} \rho u^{2}
$$

where $\rho$ and $u$ are the density and velocity of air inside the wind tunnel, respectively.

Figure 4 shows the relation between the dynamic pressure and pressure transducer voltage. Results showed that the pressure was linearly related to the pressure transducer voltage, which is consistent with the transducer specifications. The Pitot tube was then placed at the exit of the contraction to measure velocity profile at the entrance of the airway tree along two perpendicular axes (in the vertical and horizontal directions).

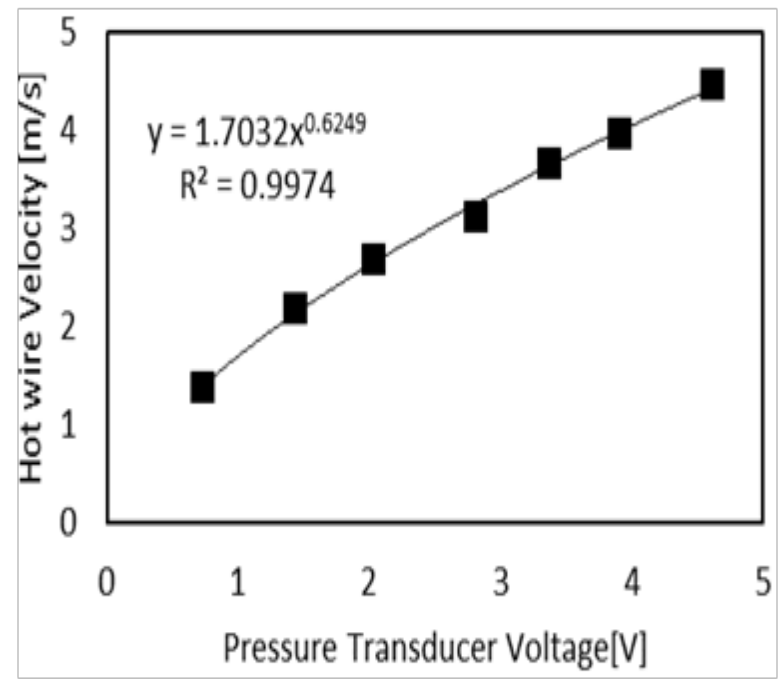

Figure 3 Hot wire velocities plotted against pressure transducer voltage. The relation between the velocities and pressure transducer voltages was found to be a power of $\sim 0.6$.

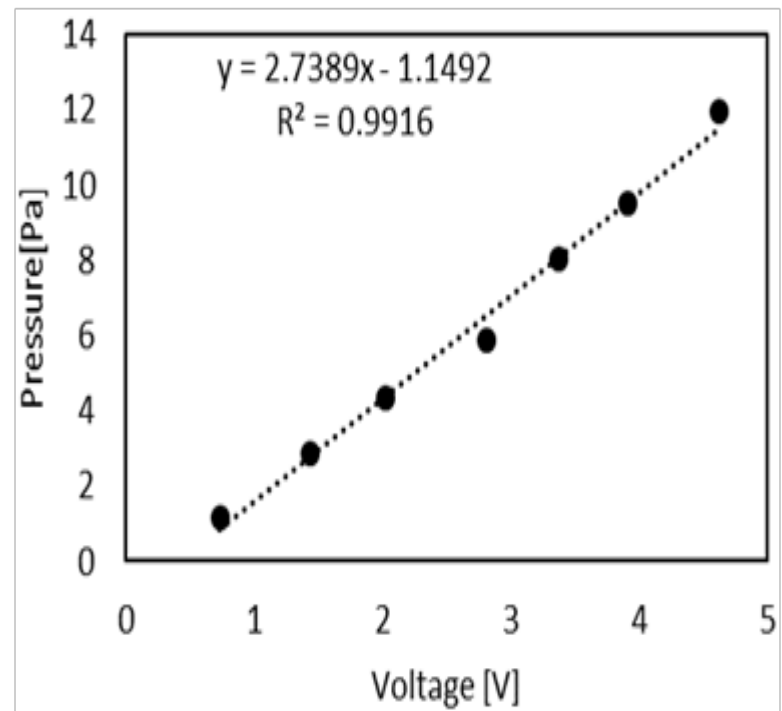

Figure 4 Dynamic pressure vs pressure transducer voltage. This relation was used as the calibration equation for the pressure transducer.

Figure 5 shows that the velocity profile was approximately flat at the entrance along both axes. Figure 6 shows the static pressure in the trachea for different flow rates, which equals the pressure loss in the model. The resulting quadratic equation of the regression line shows the relation between pressure loss and flow rate.

Figure 7 shows the spectrum (using FFT) of the sound recorded at the trachea for different flow rates. Results showed that the dominant frequency ranged from $1840 \mathrm{~Hz}$ to $1870 \mathrm{~Hz}$ for flow rates from $0.20 \mathrm{lit} / \mathrm{s}$ to $0.55 \mathrm{lit} / \mathrm{s}$. The sound recorded at no flow condition showed dominant frequency around $120 \mathrm{~Hz}$, suggesting that the background noise level of the system occurs at low frequencies with low amplitudes compared to the sound measured in the model. The spectrum was calculated using FFT. When pulsatile flow is to be studied, time frequency distributions ${ }^{29,30}$ may provide a better method to estimate the frequency spectrum. 


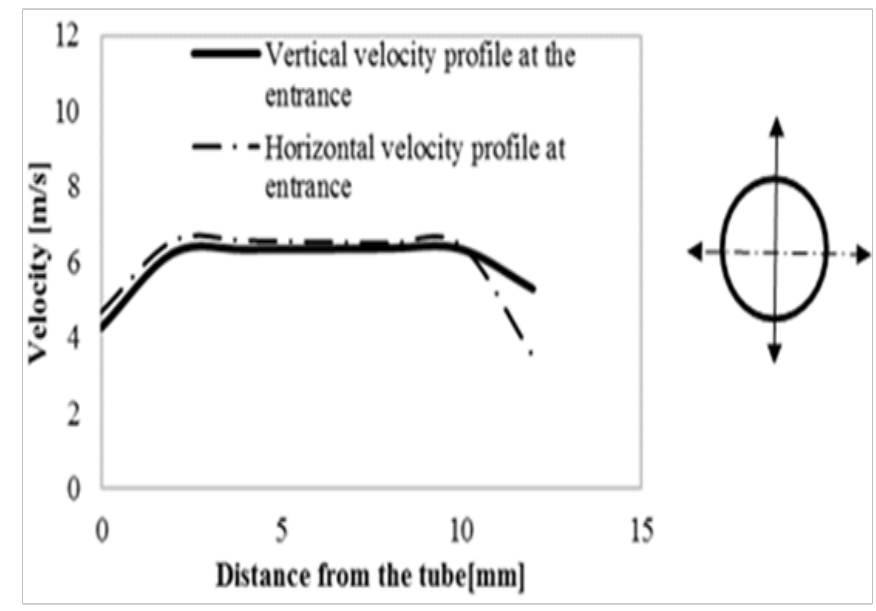

Figure $\mathbf{5}$ Velocity profile measurements at the inlet of the airway tree along the vertical and horizontal axes.

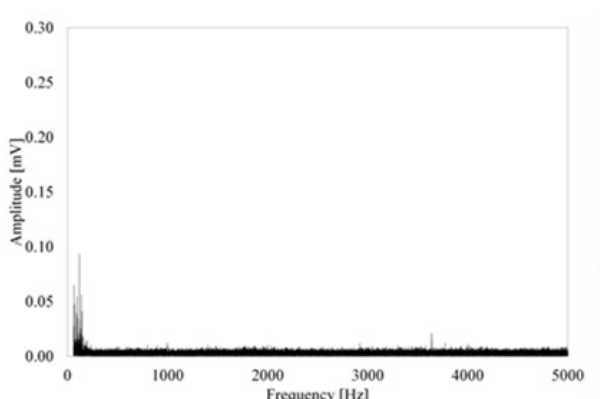

(a)

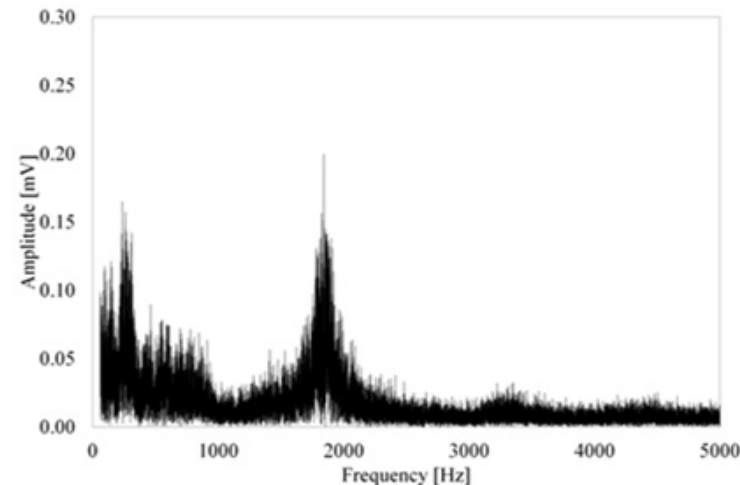

(d)

Figure 7 Airflow sounds spectral plot at trachea (Figure 2) for flow rate of
A. 0 lit/s (no flow)
B. $0.204 \mathrm{lit} / \mathrm{s}$
C. $0.374 \mathrm{lit} / \mathrm{s}$
D. $0.499 \mathrm{lit} / \mathrm{s}$
E. $0.546 \mathrm{lit} / \mathrm{s}$.

\section{Discussion}

The current study used a miniature model of pig airways to investigate the pressure loss and sound generated in the airways. The small diameters of the miniature model may have allowed an increased pressure loss, which can be measured with higher accuracy compared to large diameter models. Results showed that the static

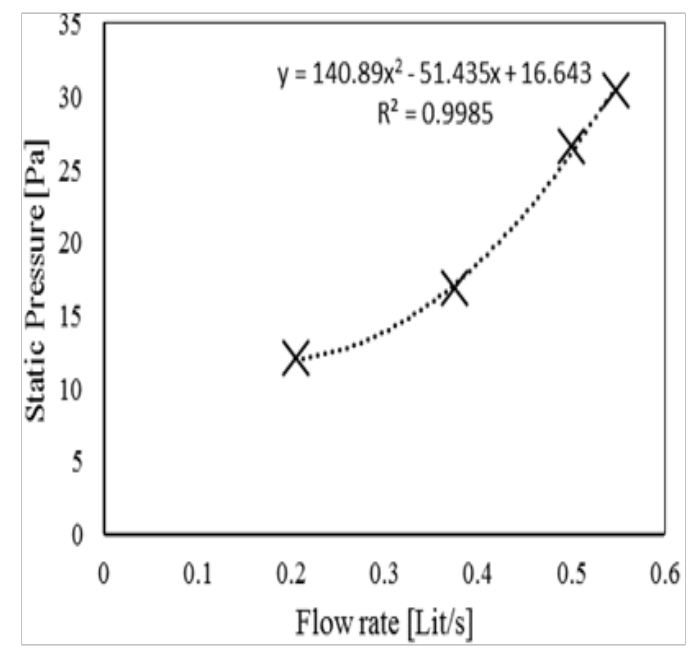

Figure 6 Pressure loss in the mode at the trachea for different flow rates.

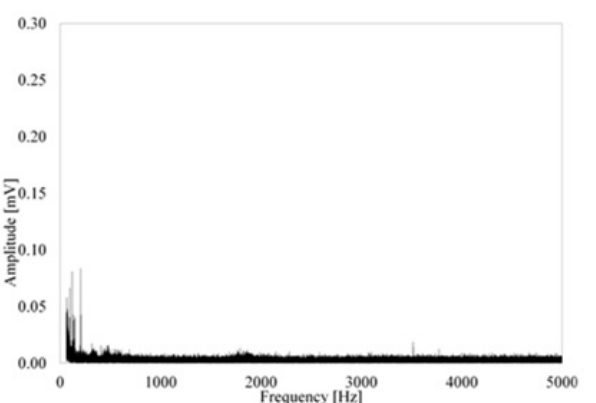

(b)

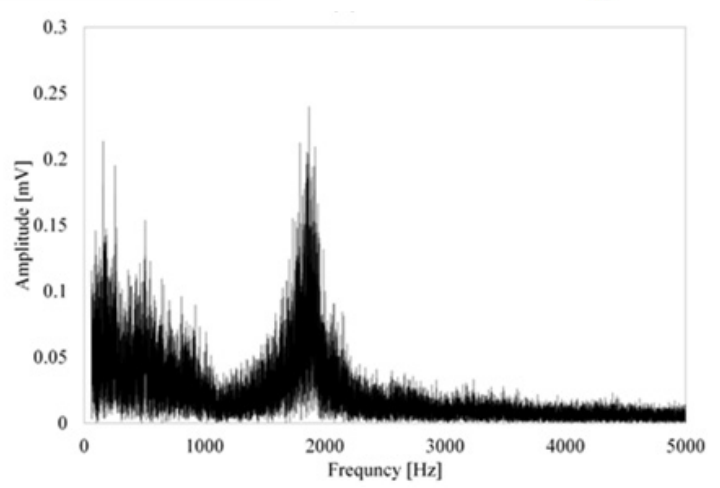

(e)

pressure at the trachea was small $(<30 \mathrm{~Pa})$ for the range of flow rates considered. The pressure difference in individual airway branches is expected to be smaller and a pressure transducer capable of measuring even lower differential pressures would be needed. Hot wire anemometer was chosen as the reference velocity measuring device since it has a calibration certificate provided by manufacturer. The pressure transducer used in this experiment is a diaphragm 
pressure transducer. The orientation of the pressure transducer can affect the measurements. Hence, the transducer was oriented such that the diaphragm is vertical to help nullify the effect of gravity on the diaphragm. Reducing pressure errors is important especially when measuring low pressure values like those encountered in the current study. The probe microphone was calibrated according to manufacturer's instruction. This was done by connecting the probe microphone to a calibrator supplied by the manufacturer, which generates a $1 \mathrm{kHz} 94 \mathrm{~dB}$ audio signal. The probe microphone output was measured by the data acquisition system and the signal was found to be within the manufacturer's specifications. In addition, the pressure transducer voltage was found to be linearly proportional to the measured pressure as stated by the manufacturer specifications. When calibrating the pressure transducer, its output was found to be proportional to the square of the velocity, which is consistent with theory. A small pitot tube (diameter $=1.6 \mathrm{~mm}$ ) was used to minimize disturbance to the flow to be measured.

The velocity profile at the model inlet was predominantly flat along two perpendicular axes. If fully developed inlet flow is desired a longer entrance length would be added. While the flow rate in this experiment was unidirectional and steady, a pulsatile flow will be studied in future investigations to understand the pressure and sound generation characteristics under conditions that are more similar to normal breathing. Figure 7 shows that the amplitude of the sound recorded in the trachea increased as the flow increased but dominant frequencies did not appear to significantly change. The dominant frequency was found to be around $1840 \sim 1870 \mathrm{~Hz}$ (using FFT) and disappeared when the flow was absent. At no flow condition, the dominant frequency was around $120 \mathrm{~Hz}$, which may be due to the environmental noise or noise in the measurement system. Similar experiments are warranted to study pulsatile flow in airways of different sizes.

\section{Conclusion}

The primary objective of the current study is to investigate the pressure loss and sound generated in a realistic miniature pig airway tree for different flow rates. The results showed that the pressure loss increased with increasing flow rate. The sound measured at the trachea had a dominant frequency around 1840 to $1870 \mathrm{~Hz}$ for flow rates of $0.2-0.55$ lit/s. Since the airway geometry appears to be significantly different among species, sound generation and pressure loss in pig and human airway trees can be different and, therefore, geometries need to be studied separately. The current study used unidirectional flow with flat inlet velocity profile. Actual tracheal inlet flow is pulsatile and is likely to have complex profiles due to effect of upper airways and vocal cords. Further studies may be warranted to document sound generation under these conditions.

\section{Acknowledgements}

This study was supported by NIH Grant R01 EB012142, R43 HL099053.

\section{Conflict of interest}

The authors declare no conflict of interest.

\section{References}

1. Dai Z, Peng Y, Henry BM, et al. A Comprehensive computational model of sound transmission through the porcine Lung. J Acoust Soc Am. 2014;136(3):1419.
2. Dellinger RP, Parrillo JE, Kushnir A, et al. Dynamic visualization of lung sounds with a vibration response device: a case series. Respiration. 2008;75(1):60-72.

3. Mansy HA, Royston TJ, Balk RA, et al. Pneumothorax detection using computerized analysis of breath sounds. Med Biol Eng Comput. 2002;40(5):526-532.

4. Mansy HA, Royston TJ, Balk RA, et al. Pneumothorax detection using pulmonary acoustic transmission measurements. Med Biol Eng Comput. 2002;40(5):520-525.

5. O'Connor CJ, Mansy H, Balk RA, et al. Identification of endotracheal tube malpositions using computerized analysis of breath sounds. Anesth Analg. 2005;101(3):735-739.

6. Pasterkamp H, Kraman SS, Wodicka GR. Respiratory sounds. Advances beyond the stethoscope. Am J Respir Crit Care Med. 1997;156(3 Pt 1):974-87.

7. Hansen A Mansy, Md Khurshidul Azad, Brandon McMurray, et al. Investigating the geometry of pig airways using computed tomography. SPIE Proceedings. 2015;9417:1-7.

8. Mansy HA, Balk RA, Warren WH, et al. Pneumothorax effects on pulmonary acoustic transmission. J Appl Physiol. 2015;119(3):250-257.

9. Kraman SS, Wang PM. Airflow-generated sound in a hollow canine airway cast. Chest. 1990;97(2):461-466.

10. Jukka Räsänen, Michael E Nemergut, Noam Gavriely. Changes in breath sound power spectra during experimental oleic acid-induced lung injury in pigs. J Appl Physiol. 2014;116:61-66.

11. Acikgoz S, Ozer MB, Royston TJ, et al. Experimental and computational models for simulating sound propagation within the lungs. $J$ Vib Acoust. 2008; $130: 45263$

12. Zoujun Dai, Ying Peng, Hansen A Mansy, et al. Experimental and computational studies of sound transmission in a branching airway network embedded in a compliant viscoelastic medium. Journal of Sound and Vibration. 2015;339:215-29.

13. Gamage P, Mansy HA. A Computation Model of Airflow in the Main Airways of the Lung. BMES Annu Meet, USA: Tampa Convention Center; 2015.

14. Brian Henry, Zoujun Dai, Ying Peng, et al. Investigation of pulmonary acoustic simulation: comparing airway model generation techniques. SPIE Medical Imaging. 2014;9038:180-190

15. Ozer MB, Acikgoz S, Royston TJ, et al. Boundary element model for simulating sound propagation and source localization within the lungs. $J$ Acoust Soc Am. 2007;122(1):657-661.

16. Royston TJ, Mansy HA, Sandler RH. Excitation and propagation of surface waves on a viscoelastic half-space with application to medical diagnosis. J Acoust Soc Am. 1999;106(6):3678-3686.

17. Royston TJ, Zhang X, Mansy HA, et al. Sandler RH (2002) Modeling sound transmission through the pulmonary system and chest with application to diagnosis of a collapsed lung. J Acoust Soc Am. 2002;111(4):1931-1946.

18. Zhang X, Royston TJ, Mansy HA, et al. Radiation impedance of a finite circular piston on a viscoelastic half-space with application to medical diagnosis. J Acoust Soc Am. 2001;109(2):795-802.

19. Dai Z, Peng Y, Mansy HA, et al. Comparison of poroviscoelastic models for sound and vibration in the lungs. J Vib Acoust. 2014;136(5):5101215101211.

20. Peng Y, Dai Z, Mansy HA, et al. Sound transmission in the chest under surface excitation-An experimental and computational study with diagnostic applications. Med Biol Eng Comput. 2014;52(8):695-706. 
21. Peng Y, Dai Z, Mansy HA, et al. Sound transmission in porcine thorax through airway insonification. Med Biol Eng Comput. 2015;54(4):675689.

22. Isabey D, Chang HK. Steady and unsteady pressure-flow relationships in central airways. J Appl Physiol Respir Environ Exerc Physiol. 1981;51(5):1338-1348.

23. Ben Jebria A, Tabka Z, Techoueyres P. Steady pressure-flow relationship in a cast of the upper and central human airways. Int J Biomed Comput. 1987;20(3):211-224.

24. Olson DE, Dart GA, Filley GF. Pressure drop and fluid flow regime of air inspired into the human lung. J Appl Physiol. 1970;28(4):482-494.

25. Azad Md, Mansy HA. Probing the Angles and Diameters of Pig Airway Branching Using Computed Tomography. BMES Annu Meet, USA: Tampa Convention Center; 2015.
26. Azad MK, Mansy HA, Gamage P. Geometric features of pig airways using computed tomography. Physiol Rep. 2016;4(20):e12995.

27. Azad MK, Mansy HA. Generation of pig airways using rules developed from the measurements of physical airways. J Bioeng Biomed Sci. 2016;6(4):203.

28. Azad Md, Gamage PT, Mansy HA. Diameters and Lengths of Pig Airways Using Computed Tomography. Orlando, USA: EMBC; 2016.

29. Amirtaha Taebi, Hansen A Mansy. Time-frequency Description of Vibrocardiographic Signals. $38^{\text {th }}$ Annual International conference of the IEEE engineering in medicine and biology society, Orlando, USA; 2016.

30. Taebi A, Mansy HA. Effect of noise on time-frequency analysis of vibrocardiographic signals. J Bioeng Biomed Sci. 2016;6(4):202. 